\title{
CONSEJO NACIONAL DE LA MAGISTRATURA
}

\section{César Delgado Barreto}

\section{ELECCION DE MAGISTRADOS SEGUN LA CONSTITUCION DE 1933}

Los artículos 222 y 223 de la Constitución de 1933 disponian que la facultad de elegir a los Magistrados correspondía según su jerarquía al Poder Legislativo o al Poder Ejecutivo, vale decir en última instancia al Poder Político.

Los Vocales y Fiscales de la Corte Suprema eran elegidos por el Congreso entre diez candidatos propuestos por el Poder Ejecutivo (Art. 222). Mientras que los Vocales y Fiscales de las Cortes Superiores eran nombrados por el Poder Ejecutivo a propuesta, en terna doble, de la Corte Suprema; los Jueces de Primera Instancia y los Agentes Fiscales eran nombrados por el Poder Ejecutivo, pero a propuesta, en terna doble de la respectiva Corte Superior (Art. 223).

La elección de Magistrados en la Constitución de 1933 mantuvo el sistema consagrado en la mayoría de nuestras Constituciones anteriores que sometieron el Poder Judicial al Poder Político, en virtud del sistema de nombramientos judiciales. Excepcionalmente las Constituciones de 1826, 1834 y 1857 limitaron la excesiva injerencia del Poder Ejecutivo, pero en última instancia aún en estos casos, el Poder Político expresado en el Poder Legislativo, tenía la decisión final en la elección de magistrados.

La experiencia vivida bajo este sistema ha sido muy aleccionadora. Al respecto el Dr. Alberto D'Angelo en su Memoria como Presidente del Consejo Nacional de Justicia, correspondiente a 1972-73, nos dice: "Estaba en el consenso público que debía terminar el bochornoso espectáculo que representaba el desfile de magistrados en el Palacio Legislativo en demanda de votos para la elección de Vocales Supremos. $O$ la denigrante espera en las salas ministeriales o de personas influyentes para solicitar su nombramiento de Vocal Superior o de Juez de Primera Instancia. Esto era entonces lo que contaba y no las calidades personales del futuro magistrado".

A lo anteriormente expresado hay que añadir que a pesar de que ei Art. 69 de la Constitución disponia que "Todos los derechos individuales y sociales reconocidos por la Constitución, dan lugar a la acción de habeas corpus" en la práctica, pocas veces prosperó esta acción debido al sometimiento del Poder Judicial al Poder Ejecutivo, que tenía su origen en el sistema de nombramientos judiciales.

\section{EL CONSEJO NACIONAL DE JUSTTCIA}

La necesidad de que la justicia sea administrada rectamente presupone su autonomía frente a los otros órganos del Estado. Montesquieu decía: no hay libertad, si el poder de juzgar no está separado del Poder Legislativo y del Ejecutivo. 
Desde hace cerca de medio siglo, abogados, juristas y magistrados han venido luchando en el Perú por lá independencia del Poder Judicial. La Comisión Villarán nombrada en 1931 para formular un anteproyecto de la Nueva Constitución propuso la creación de un Consejo Nacional de justicia, como organismo autónomo, ajeno en su constitución a los otros Poderes del Estado para efectuar los nombramientos judiciales, con excepción de los Vocales Supremos que serían elegidos por el Senado, entre los propuestos en dos ternas formuladas una por la Corte Suprema y la otra por el Consejo Nacional de Justicia.

Los Constituyentes dejaron de lado el anteproyecto Villarán y se inclinaron por el dictamen en mayoria sobre organización del Poder Judicial que propuso el mantenimiento del sistema vigente, a pesar de que los resultados negativos ya eran conocidos.

Desde 1933 hasta 1969 se presentaron varios proyectos para modificar los Arts. 222 y 223 de la Constitución de 1933, siendo los más importantes: el presentado en 1945 por el Senador Manuel J. Bustamante de la Fuente. En 1948 el Dr. Luis Quiñe Arista elaboró un Anteproyecto de la Ley Orgánica del Poder Judicial, el cual contemplaba la creación de un Consejo Nacional de Justicia, en la Exposición de Motivos del mencionado Anteproyecto se pregunta el autor: "¿cuál es el objeto de la creación de este Consejo Nacional de Justicia?. La respuesta no se hace esperar. Primordialmente, establecer la independencia funcional del Poder Judicial, suprimir para el futuro la intervención del Poder Ejecutivo y del Poder Legislativo en los nombramientos judiciales, vale decir de la política y de las influencias". En 1956, el Dr. Mario Alzamora Valdez presentó a la Cámara de Diputados un Proyecto de Reforma Constitucional sobre el sistema de nombramientos judiciales y el cual incluía la creación del Consejo Nacional de Justicia. En 1959 el Dr. Ricardo Bustamante y Cisneros al asumir la Presidencia de la Corte Suprema, expresó que: "Es oportuno sustituir el actual sistema sobre provisión de cargos judiciales, caracterizado por la injerencia de los Poderes Ejecutivo y Legislativo, con la creación del Consejo "Nácional de Justicia".

En los Congresos Nacionales de Abogados realizados en Lima (1955), Trujillo (1957), Arequipa (1961), Piura (1964), Cuzco (1968) y Callao (1969) se aprobaron ponencias que preconizaban también la necesidad de un Consejo Nacional de Justicia que tuviese a su cargo la elección de magistrados.

Por el Decreto Ley No. 18060, de fecha 23/12/69 se creó el Consejo Nacional de Justicia, integrado por los siguientes delegados: dos del Poder Ejecutivo, dos del Poder Legislativo, dos del Poder Judicial, uno de la Federación Nacional de Colegios de Abogados, uno del Colegio de Abogados de Lima y uno por cada Programa Académico de Derecho de las dos universidades nacionales más antiguas (Art. 7). Leyes posteriores han reducido sus miembros a ocho al haber prescindido de los delegados del Colegio de Abogados de Lima y de la Universidad Nacional del Cuzco. 
La función del Consejo Nacional de Justicia es la de elegir a los magistrados de todo el Poder Judicial de la República, con excepción de los Jueces de Paz y sujetándose al sistema de propuesta vigente.

Por Decreto l.ey No. 18831 del $13 / 4 / 71$ se expide la Ley Orgánica del Consejo Nacional de Justicia ampliándose su jurisdicción y sus funciones, inciuyéndose la provisión de magistraturas de los Fueros Agrario y Privativo de Trabajo y a los Jueces Coactivos.

E] Art. 14 de su Ley Orgánica da al Consejo, de oficio o a instancia de parte, la facultad de instaurar proceso disciplinario en contra de los miembros del Poder Judicial, con excepción de los Jueces de Paz no Letrados, de los Fueros Agrario y de Trabajo y de los Jueces Coactivos. Las sanciones disciplinarias susceptibles de ser impuestas son las señaladas en el Capítulo II del Título VIII de la Ley Orgánica del Poder Judicial No. 14605.

El Art. 15 de su Ley Orgánica otorga al Consejo derecho de iniciativa en la formación de leyes destinadas a perfeccionar el ordenamiento jurídico nacional vigente.

Con la creación del Consejo Nacional de Justicia se dió sin lugar a dudas un paso muy importante en la autonomía del Poder Judicial. Sin embargo, encontramos en su Ley Orgánica dos deficiencias sustanciales en lo que respecta a la elección y al nombramiento de los magistrados.

La primera se refiere a la participación en su seno de dos delegados del Poder Ejecutivo y del Poder Legislativo. Que aunque sólo sumaban cuatro, de un total de diez miembros, implicaba la intervención del Poder Político en la elección de magistrados. Esto se agravó, cuando mediante la expedición del D.L. 21464 del 13/4/76 se redujo a ocho el número de Consejeros, al haberse excluido a dos delegados que representaban a un Colegio de Abogados y a un Programa de Derecho, quedando paritariamente la representación del Poder Político con relación a los otros miembros.

La segunda deficiencia sustancial es que si bien los magistrados son elegidos por el Consejo Nacional de Justicia, su nombramiento lo hacía el Poder Político. Se pensaba que este respetuoso de su propia ley lo único que haría era nombrar a los miembros elegidos. Sin embargo, se dió en noviembre de 1976 el increíble caso de un Vocal Supremo elegido por el Consejo, que no fue nombrado y en su lugar se nombró a uno que no había concursado. Desde esa fecha el Consejo Nacional de Justicia vivió bajo la espada de Damocles, ya que sabia de que en el caso de que eligiese a un magistrado que no contaba con el beneplácito del Poder Político, éste simplemente no lo nombraba.

Este incalificable atropello que motivó la renuncia irrevocable del Presidente y Vice Presidente del Consejo, ha puesto en evidencia la necesidad que no sólo la elección, sino también el nombramiento debe recaer exclusivamente en el Organismo especializado creado por la ley para estos efectos. 
El Capítulo X del Título IV de la Constitución de 1979 se ocupa del Consejo Nacional de la Magistratura, el cual está integrado exclusivamente por magistrados (el Fiscal de la Nación y dos Representantes de la Corte Suprema), abogados (un representante de la Federación Nacional de Colegios de Abogados del Perú y un representante del Colegio de Abogados de Lima) y catedráticos (dos representantes de las Facultades de Derecho de la República (Art. 246) lo que significa un avance con respecto al Consejo Nacional de Justicia, al no estar compuesto por Representantes del Poder Político.

El mismo artículo 246 dispone que los miembros del Consejo "son remunerados con dietas que se fijan en el Presupuesto General de la República", lo cual, implica que su labor no la van a desempeñar a dedicación exclusiva, sino que paralelamente van a continuar en el ejercicio profesional de la abogacía, con el consiguiente riesgo de utilizar su gran influencia en beneficio de las causas que patrocinen, y aunque no ejerzan ninguna presión el solo hecho de que figure su nombre como abogados va inevitablemente a mediatizar a los magistrados que aspiran lógicamente a ascender en su carrera.

A fin de evitar este grave peligro es que el Art. 19 de la Ley Orgánica del Consejo Nacional de Justicia dispuso que sus miembros trabajasen a dedicación exclusiva, prohibiéndoles el ejercicio de la profesión de abogado.

El Art. 245 de la Constitución vuelve a entronizar en el sistema de nombramiemntos judiciales el factor político partidario al disponer que el Presidente de la República nombra a los magistrados de toda la jerarquía, a propuesta del Consejo Nacional de la Magistratura, requiriéndose ratificación del Senado, cuando se trata de los Vocales de la Corte Suprema.

Comentando este artículo constitucional el Dr. Artemio Alvarez Benavides en su Memoria como Presidente del Consejo Nacional de Justicia, correspondiente a 1978-79 expresa acertadamente: "Formuladas las propuestas por el Consejo Nacional de la Magistratura o los Consejos Distritales no es difícil suponer el criterio con que el Presidente realizará los nombramientos de jueces. Si el Presidente es elevado a la más alta magistratura de la República por el partido político al que pertenece y se da el caso que se le propone un correligionario entre otros que no tienen esa característica ¿cuál será el criterio con que se decida el nombramiento? lo inconveniente del sistema establecido resulta mucho más evidente cuando se trata del nombramiento de Vocales Supremos, los que deberán ser ratificados en su nombramiento por el Senado, organismo absolutamente político, que habrá de actuar con ese criterio como no puede ser de otro modo".

El sistema de nombramientos judiciales establecido por la Constitución de 1979 significa sin lugar a dudas un paso atrás en la lucha por la independencia del Poder Judicial. Desgraciadamente la concupiscencia de poder obnubiló 
a la dirigencia de los partidos que tenían la mayoria en la Asamblea Constituyente, optando por la alternativa de tener un Poder Judicial obsecuente, sin darse cuenta del precio que harían pagar a todo el país, e incluso a ellos mismos, cuando por las vicisitudes propias de la vida política perdiesen el poder en favor de sus adversarios politicos.

Si la justicia es la piedra angular de la vida jurídica de un país, es necesario que sea administrada con rectitud y equidad, y esto solo es posible si el órgano encargado de su fiel cumplimiento goza de autonomía.

Para alcanzar este logro se han propuesto diversos sistemas, siendo los principales, la elección popular que si bien es democrático tiene el peligro de hacer depender el nombramiento de los magistrados también en los partidos políticos; el de la cooptación, o sea la designación de los magistrados por el propio Poder Judicial, y cuyo mayor inconveniente radica en el riesgo de que se forme una casta judicial conservadora e inhabil de aplicar el derecho a las circunstancias cambiantes de una sociedad en continua transformación. El otro sistema es que la elección y nombramiento recaiga en un organismo autónomo integrado exclusivamente por abogados, catedráticos y magistrados a dedicación exclusiva, que hasta ahora es el mejor de los sistemas que se han formulado.

Si concordamos lo dispuesto en los artículos 245,246 y 251 de la Constitución de 1979 se encuentra un auténtico círculo vicioso que impediría a la postre la instalación del Consejo Nacional de la Magistratura. En efecto, según lo dispuesto en el art. 251 el Fiscal de la Nación es nombrado con el mismo procedimiento establecido para los integrantes del Poder Judicial, vale decir que es nombrado por el Presidente de la República, a propuesta del Consejo Nacional de la Magistratura, pero como hemos visto el Consejo es presidido por el Fiscal de la Nación, lo que implica que el Consejo no puede funcionar mientras no sea nombrado el Fiscal de la Nación, y éste por su parte no puede ser nombrado mientras no sea propuesto por el Consejo Nacional de la Magistratura.

E1 Art. 248 trata de la función contralora de la Corte Suprema con respecto a la conducta funcional de los jueces. Por consiguiente este artículo no tiene nada que ver con el Consejo Nacional de la Magistratura, ya que el lugar que lógicamente le corresponde es el Capítulo IX del Título IV de la Constitución dedicado al Poder Judicial. Por último, el Art. 249 da al Consejo la atribución de recibir denuncias sobre la actuación de los Vocales de la Corte Suprema, pero no le confiere la facultad de sancionar, ya que lo único que puede hacer es cursar la denuncia ante el Fiscal de la Nación, si hay presunción de delito y a la propia Corte Suprema, para la aplicación de medidas de carácter disciplinario.

El Art. 14 de la Ley Orgánica del Consejo Nacional de Justicia le confiere la atribución de investigar y de sancionar a los miembros del Poder Judicial, de los Fueros Agrarios y de Trabajo y a los Jueces Coactivos, con excepción de los Jueces de Paz no Letrados. 
Es conveniente el haber circunscrito la atribución del Consejo de recibir denuncias exclusivamente sobre la conducta funcional de los Vocales de la Corte Suprema, pues con respecto al resto de la jerarquía judicial es competente el Organismo de Control.

Lo que sí es inconveniente, es limitar la facultad del Consejo Nacional de la Magistratura a calificar las denuncias sobre la actuación de los Magistrados de la Corte Suprema, negándole la facultad de sanción. Es más idóneo para los efectos del control que no sean los propios Vocales de la Corte Suprema los que investiguen y sancionan a sus miembros, sino un organo independiente, que por ser tal, tiene una mayor imparcialidad que asegura una más justa investigación y sanción. 